\title{
Serial testing with the interferon- $\gamma$ release assay in Portuguese healthcare workers
}

\author{
José Torres Costa $\cdot$ Rui Silva $\cdot$ Raul Sá $\cdot$ \\ Maria João Cardoso $\cdot$ Albert Nienhaus
}

Received: 20 April 2010 / Accepted: 9 August 2010 / Published online: 19 August 2010

(C) The Author(s) 2010. This article is published with open access at Springerlink.com

\begin{abstract}
Objectives Evidence for the utility of the new Mycobacterium tuberculosis (MTB) specific IFN- $\gamma$ release assays in diagnosing latent tuberculosis infection (LTBI) is growing. However, data concerning conversion and reversion rates in serial testing of healthcare workers (HCWs) with an interferon- $\gamma$ release assay are sparse.

Methods Between February 2007 and September 2009, $670 \mathrm{HCWs}$ in the University Hospital of Porto, Portugal were tested at least twice with QuantiFERON-TB ${ }^{\circledR}$ Gold In-Tube (QFT) for LTBI. The tuberculin skin test (TST) was performed simultaneously. QFT was considered positive if INF- $\gamma \geq 0.35 \mathrm{IU} / \mathrm{mL}$. TST conversion was defined as an increase $\geq 10$ or $\geq 6 \mathrm{~mm}$ compared to a baseline TST $<10 \mathrm{~mm}$.
\end{abstract}

J. Torres Costa $\cdot$ R. Silva $\cdot$ R. Sá

Occupational Health Division, Hospital S. João,

Alameda Professor Hernâni Monteiro, Porto, Portugal

J. Torres Costa $\cdot$ R. Silva

Allergy and Clinical Immunology Division, Hospital S. João,

Alameda Professor Hernâni Monteiro, Porto, Portugal

J. Torres Costa $\cdot$ R. Silva $\cdot$ M. J. Cardoso

Faculty of Medicine, Porto University,

Alameda Professor Hernâni Monteiro, Porto, Portugal

M. J. Cardoso

Clinical Pathology Division, Hospital S. João,

Alameda Professor Hernâni Monteiro, Porto, Portugal

A. Nienhaus $(\bowtie)$

Institute for Health Services Research in Dermatology

and Nursing, University Medical Center Hamburg-Eppendorf,

Martinistraße 52, 20246 Hamburg, Germany

e-mail: a.nienhaus@uke.uni-hamburg.de
Results The second QFT was positive in $4.8 \%$ of the 376 HCWs with an INF- $\gamma$ concentration at baseline below $0.1 \mathrm{IU} / \mathrm{mL}$ but in $48.8 \%$ of the $41 \mathrm{HCWs}$ with an INF- $\gamma$ concentration of 0.2 to $<0.35 \mathrm{IU} / \mathrm{mL}$. Out of $74 \mathrm{HCWs}$ with a baseline INF- $\gamma$ concentration $\geq 3.0 \mathrm{IU} / \mathrm{mL}, 4(5.4 \%)$ reversed while 27 out of 55 HCWs (49\%) with a baseline INF- $\gamma$ concentration $\geq 0.35$ to $<0.7 \mathrm{IU} / \mathrm{mL}$ reversed to a negative QFT. Those $61 \mathrm{HCWs}$ with TST conversion (increase $\geq 10 \mathrm{~mm}$ ) were most often $(78.7 \%)$ negative in both consecutive QFTs.

Conclusion Our data suggests the use of an uncertainty zone between 0.2 and $0.7 \mathrm{IU} / \mathrm{mL}$ in serial testing with QFT. As long as the knowledge regarding disease progression in QFT-positive persons is limited, persons pertaining to this zone should be retested before being offered preventive chemotherapy.

Keywords Serial testing · Interferon- $\gamma$ release assay · Tuberculosis $\cdot$ Healthcare workers

\section{Introduction}

The increased risk of tuberculosis (TB) in healthcare workers is well known (Seidler et al. 2005). Therefore, screening HCWs for latent TB infection (LTBI) and preventive chemotherapy is a cornerstone of TB prevention programs (CDC 2005). However, the conventional tuberculin skin test (TST) has known limitations in accuracy and reliability. Furthermore, interpretation of serial TST results is complicated by non-specific variation and because of its intradermal application, by potential boosting from precedent tests (Pai et al. 2007). The development of the interferon- $\gamma($ INF- $\gamma$ ) release assays (IGRA) is welcomed as a means of overcoming this problem. The IGRAs allow 
ex-vivo testing and therefore are not prone to boosting. In addition, the IGRAs are highly specific, giving them valuable advantages over the TST especially in Bacillus Calmette-Guérin (BCG)-vaccinated populations (Diel et al. 2006; Nienhaus et al. 2008).

As with the TST, IGRA results are determined by several factors: precision of measurement technique, intrapersonal biological variation, new infection (conversion), transient infection (Ewer et al. 2006) or transition of Mycobacterium tuberculosis (MTB) from replication to a dormant state no longer stimulating cell-mediated immune response (reversion). MTB cannot be directly observed in the body. Therefore, its presence and replication activity can only be measured indirectly by antigenspecific response in TST or IGRA. For the TST, it is common sense that test interpretation in serial testing should be based on a comparison between actual and previous TST results. Depending on circumstances, an increase in TST $\geq 6 \mathrm{~mm}$ (Menzies 1999) or $\geq 10 \mathrm{~mm}$ (ATS 2000) is believed to indicate MTB presence and activity. Preliminary data showed that, similar to TST, an easy positive/ negative interpretation of serial IGRA is not warranted (Pai et al. 2006) and a more sophisticated approach to IGRA interpretation in serial testing is needed. However, data on IGRA interpretation in serial testing is sparse. The few published studies available are rather small, allowing limited conclusions only (Hill et al. 2007; Franken et al. 2007; Cummings et al. 2009). So far, different 'uncertainty zones' for QuantiFERON-TB ${ }^{\circledR}$ Gold In-Tube (QFT), one of the two commercially available IGRAs, have been proposed. Based on the Indian data, a person whose IFN- $\gamma$ result increased from $<0.20$ and exceeded $0.50 \mathrm{IU} / \mathrm{mL}$ on the repeat test was considered to have a 'true conversion'. Likewise, a person whose IFN- $\gamma$ result decreased from $>0.50$ and fell to $<0.20 \mathrm{IU} / \mathrm{mL}$ was considered to have a 'true reversion' (Pai et al. 2009). Based on South African data, it was suggested that an increase in IFN- $\gamma$ response from below $0.35 \mathrm{IU} / \mathrm{mL}$ to above $0.70 \mathrm{IU} / \mathrm{mL}$ for the QFT assay could be used to define conversions (van Zyl-Smit et al. 2009). Because high spontaneous reversion rates were reported, when the first QFT showed INF- $\gamma$ between 0.35 and $0.7 \mathrm{IU} / \mathrm{mL}$ (Yoshiyama et al. 2009), it is unknown to what extent people falling into this category benefit from chemotherapy. In our follow-up study, we analyzed conversion and reversion rates in serial testing of $\mathrm{HCWs}$ with QFT, depending on baseline concentration of INF- $\gamma$ and TST variation as well as for different definitions of conversions and reversions. Assuming that a small variation in baseline INF- $\gamma$ concentration should not result in high changes to the conversion and reversion rates, we tried to derive an uncertainty zone around the cutoff for the QFT to be used in serial testing.

\section{Materials and methods}

Study setting and study subjects

The population of this follow-up study comprises all workers of the Hospital S. João who participated in TB screening from February 2007 through September 2009. The hospital is located in the northern part of Portugal and serves as a referral center for TB. On average, $250 \mathrm{~TB}$ patients are treated per year and a total of 32,000 patients are admitted for all diagnosis. In addition, there are about 500,000 outpatient contacts per year. As reported from a previous study of the same hospital (Torres Costa et al. 2009), the annual incidence rate of active TB in Portuguese HCWs (192 per 100,000) was about six times higher than the one in the general population in Portugal $(32 / 100,000)$ in 2006 .

In accordance with CDC guidelines, HCWs in infection and TB wards are considered to be at high risk, workers with regular patient contacts in the other wards are considered to be at medium risk and workers with no regular patient contacts or no contacts to biological material are considered to be at low risk (CDC 2005). Upon commencement of employment, all workers are examined. HCWs considered to be at high risk are evaluated annually. All others are evaluated every second year or after known exposure to patients with active TB.

TST and IGRA have been performed simultaneously. TST was performed when the diameter of a previous TST was below $15 \mathrm{~mm}$ or when no previous TST result was known. A chest X-ray was performed when TST was $\geq 10 \mathrm{~mm}$ or IGRA was positive or in HCWs with TB symptoms.

BCG vaccination was assessed through the individual vaccination register or by scars. Following the national vaccination plan, BCG vaccination for newborns is mandatory in Portugal and until January 2000 was repeated if TST was $<5 \mathrm{~mm}$ (National Vaccination Plan 2009). Therefore, every $\mathrm{HCW}$ has been vaccinated at least once.

TST was performed by trained personnel following standard procedures. In brief, $0.1 \mathrm{~mL}(2 \mathrm{TU})$ of purified protein derivate (RT23; Statens Serum Institute, Copenhagen, Denmark) was injected intradermally at the volar side of the forearm, and the transverse diameter of the induration was read $72-96 \mathrm{~h}$ later. A diameter $\geq 10 \mathrm{~mm}$ was considered positive. A conversion in TST was defined as a TST $\geq$ $10 \mathrm{~mm}$ and an increase of $\geq 10 \mathrm{~mm}$ or less stringent $\geq 6 \mathrm{~mm}$ compared to a previous TST $<10 \mathrm{~mm}$ (Menzies 1999, ATS 2000).

Blood for the IGRA was drawn during the same appointment during which the TST and an interview were conducted. As IGRA, the QuantiFERON-TB ${ }^{\circledR}$ Gold In-Tube (QFT) assay (Cellestis Limited, Carnegie, Australia) was 
administrated following the manufacturer's protocol. Concentrations above $10 \mathrm{IU} / \mathrm{mL}$ were set to $10 \mathrm{IU} / \mathrm{mL}$ because of imprecision of measurement at these high concentrations (Pai et al. 2009). According to the manufacturers, an INF- $\gamma$ concentration $\geq 0.35 \mathrm{IU} / \mathrm{mL}$ after subtracting the NIL control is defined as a positive test result. Four different definitions for conversion and reversion were applied: (1) transgression or regression over cutoff, (2) increase from $<0.2$ to $>0.7 \mathrm{IU} / \mathrm{mL}$ or decrease from $>0.7$ to $<0.2 \mathrm{IU} / \mathrm{mL}$, (3) transgression or regression over cutoff plus change $\geq 0.35 \mathrm{IU} / \mathrm{mL}$, and (4) transgression or regression over cutoff plus change $\geq 0.50 \mathrm{IU} / \mathrm{mL}$. Observers were blinded to the results of the TST and vice versa.

\section{Statistical analysis}

For metric variables, box plots were drawn giving the median as black line in the box and the 25 and 75 percentiles as the boundaries of the box. Chi-square tests were used for categorical data. Baseline INF- $\gamma$ concentration was categorized in small increments in order to observe at which increment the highest change in conversion and reversion rates occurs. The $95 \%$ confidence intervals (CI) for proportions were calculated. If the $95 \% \mathrm{CI}$ did not overlap, differences between proportions were considered as statistically significant.

The participants gave informed consent to the participation in the study. No agreement of an ethics commission was requested because data collection was performed during routine screening procedure following normal work protection standards (CDC 2005). For study purposes, no additional tests were performed and it is not standard practice to seek ethical approval for the anonymous analysis of routine data in Portugal.

\section{Results}

The study population comprises 679 persons working in healthcare with two consecutive QFTs. The study period covers February 2007 until September 2009. Indeterminate results were observed in nine $(1.3 \%) \mathrm{HCW}$. One of these nine HCWs had indeterminate results on both occasions. The characteristics of the remaining $670 \mathrm{HCWs}$ as well as of a subgroup of $252 \mathrm{HCW}$ sho had three consecutive QFTs are given in Table 1. The subgroup is comparable to the whole group with respect to the distribution of age, gender, BCG history, profession, risk assessment, and number of TSTs during the study period.

The first and second QFTs were positive in $30.0 \%$ of the HCWs (Table 2). A conversion occurred in $11.0 \%$ of those negative in the first QFT and a reversion in $22.1 \%$ of those positive in the first QFT, if a simple dichotomous approach
Table 1 Description of the study population with two consecutive QFTs and subpopulation with three consecutive QFTs

\begin{tabular}{|c|c|c|c|c|}
\hline & \multicolumn{2}{|c|}{ Two QFTs } & \multicolumn{2}{|c|}{ Three QFTs } \\
\hline & $N$ & $\%$ & $N$ & $\%$ \\
\hline \multicolumn{5}{|l|}{ Age } \\
\hline $16-29$ & 269 & 40.1 & 95 & 37.7 \\
\hline $30-39$ & 175 & 26.1 & 68 & 27.0 \\
\hline $40-49$ & 115 & 17.2 & 49 & 19.4 \\
\hline $50-59$ & 92 & 13.7 & 34 & 13.5 \\
\hline$\geq 60$ & 19 & 2.8 & 6 & 2.4 \\
\hline \multicolumn{5}{|l|}{ Gender } \\
\hline Female & 495 & 73.9 & 188 & 74.6 \\
\hline Male & 175 & 26.1 & 64 & 25.4 \\
\hline \multicolumn{5}{|l|}{ BCG history } \\
\hline Only at birth & 182 & 27.2 & 59 & 23.4 \\
\hline One additional & 244 & 36.4 & 106 & 42.1 \\
\hline Two additional & 177 & 26.4 & 54 & 21.4 \\
\hline$\geq 3$ additional & 67 & 10.0 & 33 & 13.1 \\
\hline \multicolumn{5}{|l|}{ TB in history } \\
\hline Yes & 79 & 11.8 & 28 & 11.1 \\
\hline No & 591 & 88.2 & 224 & 88.9 \\
\hline \multicolumn{5}{|l|}{ Profession } \\
\hline Administrators & 98 & 14.6 & 38 & 15.1 \\
\hline Auxiliaries, cleaning staff & 108 & 16.1 & 49 & 19.4 \\
\hline $\begin{array}{l}\text { Technicians } \\
\quad \text { (radiology, lab, etc.) }\end{array}$ & 45 & 6.7 & 21 & 8.3 \\
\hline Nurses & 307 & 45.8 & 110 & 43.7 \\
\hline Doctors & 112 & 16.7 & 34 & 13.5 \\
\hline \multicolumn{5}{|l|}{ Risk assessment } \\
\hline Low & 94 & 14.0 & 48 & 19.0 \\
\hline Moderate & 246 & 36.7 & 80 & 31.8 \\
\hline High & 330 & 49.3 & 124 & 49.2 \\
\hline \multicolumn{5}{|l|}{ Years working in hospital } \\
\hline$<5$ & 283 & 42.2 & 101 & 40.1 \\
\hline $5 \leq 10$ & 115 & 17.2 & 44 & 17.5 \\
\hline $10 \leq 15$ & 84 & 12.5 & 33 & 13.1 \\
\hline $15 \leq 20$ & 58 & 8.7 & 27 & 10.7 \\
\hline$\geq 20$ & 130 & 19.4 & 47 & 18.7 \\
\hline \multicolumn{5}{|l|}{ TST history in last 3 years } \\
\hline No TST, old, TST $\geq 15 \mathrm{~mm}$ & 138 & 20.6 & 46 & 18.3 \\
\hline One TST & 346 & 51.6 & 143 & 56.7 \\
\hline Two TSTs & 150 & 22.4 & 52 & 20.6 \\
\hline Three TSTs & 36 & 5.4 & 11 & 4.4 \\
\hline Total & 670 & 100.0 & 252 & 100.0 \\
\hline
\end{tabular}

(negative-positive and vice versa) was chosen. Reversion and conversion rates depended on the INF- $\gamma$ concentration of the first QFTs. Conversion occurred in $4.8 \%$ of the 376 HCWs with an INF- $\gamma$ concentration at baseline below $0.1 \mathrm{IU} / \mathrm{mL}$ but in $48.9 \%$ of the $41 \mathrm{HCW}$ s with an INF- $\gamma$ 
Table 2 Results of second QFT depending on INF- $\gamma$ concentration in first QFT

\begin{tabular}{|c|c|c|c|c|c|c|}
\hline \multirow[t]{3}{*}{ 1st QFT (IU/mL) } & \multicolumn{4}{|c|}{ 2nd QFT } & \multirow{2}{*}{\multicolumn{2}{|c|}{ Total }} \\
\hline & \multicolumn{2}{|c|}{ Negative } & \multicolumn{2}{|c|}{ Positive } & & \\
\hline & $N$ & $\%$ & $N$ & $\%$ & $N$ & $\mathrm{Col} \%$ (row \%) \\
\hline$<0.1$ & 358 & 95.2 & 18 & 4.8 & 376 & 81.4 \\
\hline $0.1 \leq 0.2$ & 32 & 71.1 & 13 & 28.9 & 45 & 9.7 \\
\hline $0.2 \leq 0.35$ & 21 & 51.2 & 20 & 48.8 & 41 & 8.9 \\
\hline Neg. 1st QFT & 411 & 89.0 & 51 & 11.0 & 462 & $100.0(69.0)$ \\
\hline $0.35 \leq 0.5$ & 17 & 50.0 & 17 & 50.0 & 34 & 16.3 \\
\hline $0.5 \leq 0.7$ & 10 & 47.6 & 11 & 52.4 & 21 & 10.1 \\
\hline $0.7-1.0$ & 5 & 19.2 & 21 & 80.8 & 26 & 12.5 \\
\hline$>1-3$ & 10 & 18.9 & 43 & 81.1 & 53 & 25.5 \\
\hline$>3-7$ & 2 & 8.0 & 23 & 92.0 & 25 & 12.0 \\
\hline$>7$ & 2 & 4.1 & 47 & 95.9 & 49 & 23.6 \\
\hline Pos. 1st QFT & 46 & 22.1 & 162 & 77.9 & 208 & $100.0(31.0)$ \\
\hline All & 457 & 68.2 & 213 & 31.8 & 670 & 100.0 \\
\hline
\end{tabular}

concentration of 0.2 to $<0.35 \mathrm{IU} / \mathrm{mL}$. The same pattern is observed for reversions. In the $49 \mathrm{HCWs}$ with a baseline INF- $\gamma$ concentration $>7.0 \mathrm{IU} / \mathrm{mL}$, two reversions $(4.1 \%)$ occurred while in those $55(34+21) \mathrm{HCWs}$ with a baseline INF- $\gamma$ concentration $\geq 0.35$ to $<0.7 \mathrm{IU} / \mathrm{mL}$, about every second HCW showed a reversion. For reversion and conversion rates, a neat dose-frequency relation to the concentration at the first QFT was observed.

The diameter of the TST was positively associated with the probability of two consecutive positive QFTs. This probability increased from $10 \%$ in those with a TST $<10 \mathrm{~mm}$ to $31.7 \%$ for those with a TST $\geq 15 \mathrm{~mm}$ (Table 3). An increase in the second TST by at least $10 \mathrm{~mm}$ was seen in $61(30.7 \%)$ of those who had a first TST $<10 \mathrm{~mm}$. Of these $61 \mathrm{HCWs} 78.7 \%$ were negative in the two consecutive QFTs and 6.6\% showed a conversion in QFT (Definition 1). In those HCWs with a TST of $10 \leq 15 \mathrm{~mm}$ who were retested during the study period, four $(2.1 \%)$ showed decreases in their TST results of $\geq 10 \mathrm{~mm}$ and seven $(4.5 \%)$ of $\geq 6 \mathrm{~mm}$

Conversion and reversion rates showed statistically significant differences, depending on the definition used (Table 4). The conversion rates were highest following TST (17.9\%) and second highest when crossing the cutoff for QFT was used as a definition. The $95 \% \mathrm{CI}$ of these rates does not overlap, indicating a statistically significant difference. Using a gray zone from 0.2 to $0.7 \mathrm{IU} / \mathrm{mL}$ and excluding all those who have at least one QFT within this gray zone from calculation resulted in low conversion (3.6\%) and reversion rates $(5.2 \%)$. Somewhat higher rates were obtained when, in addition to a positive-negative approach,
Table 3 Results of first and second QFT in relation to TST and to change in TST

\begin{tabular}{|c|c|c|c|c|c|c|c|c|c|c|}
\hline \multirow[t]{3}{*}{ TST } & \multicolumn{8}{|c|}{ 1st and 2nd QFT } & \multirow{2}{*}{\multicolumn{2}{|c|}{ Total }} \\
\hline & \multicolumn{2}{|l|}{--} & \multicolumn{2}{|l|}{++} & \multicolumn{2}{|c|}{+-} & \multicolumn{2}{|c|}{-+} & & \\
\hline & $N$ & $\%$ & $N$ & $\%$ & $N$ & $\%$ & $N$ & $\%$ & $N$ & $\%$ \\
\hline 0-9 mm & 67 & 74.4 & 9 & 10.0 & 9 & 10.0 & 5 & 5.6 & 90 & 13.4 \\
\hline $10-14 \mathrm{~mm}$ & 156 & 67.8 & 42 & 18.3 & 13 & 5.7 & 19 & 8.3 & 230 & 34.3 \\
\hline$\geq 15 \mathrm{~mm}$ & 188 & 53.7 & 111 & 31.7 & 24 & 6.9 & 27 & 7.7 & 350 & 52.2 \\
\hline \multicolumn{11}{|c|}{ Increase $\mathrm{TST}^{*}$} \\
\hline$\geq 10 \mathrm{~mm}$ & 48 & 78.7 & 4 & 6.6 & 5 & 8.2 & 4 & 6.6 & $61 / 199$ & 30.7 \\
\hline$\geq 6 \mathrm{~mm}$ & 75 & 76.5 & 9 & 9.2 & 7 & 7.1 & 7 & 7.1 & 98/199 & 49.2 \\
\hline \multicolumn{11}{|c|}{ Decrease TST } \\
\hline$\geq 10 \mathrm{~mm}$ & 3 & 75.0 & 1 & 25.0 & 0 & - & 0 & - & $4 / 188$ & 2.1 \\
\hline$\geq 6 \mathrm{~mm}$ & 4 & 57.1 & 2 & 28.6 & 0 & - & 1 & 14.3 & $7 / 188$ & 4.5 \\
\hline
\end{tabular}

* First TST $<10 \mathrm{~mm}$, second TST $\geq 10 \mathrm{~mm}$ and increase or decrease compared to previous TST $\geq 10$ (6) $\mathrm{mm}$

$\%$ row percent, col \% column percent

- - both consecutive QFTs were negative

-+ first QFT was negative, second QFT was positive, and so on

a minimal chance of 0.35 or $0.5 \mathrm{IU} / \mathrm{mL}$ was requested for conversion and reversion. For all definitions, conversion rates were lower than reversion rates but the difference was statistically significant for the least stringent definition only $(1 \mathrm{a}+\mathrm{b}$, Table 4$)$. For the TST, reversion rates $(2.1$ or $3.8 \%)$ were considerably lower than conversion rates (17.9 or $22.8 \%$ ).

In the subgroup with three consecutive QFTs, the same trend was observed (Table 5) as in the whole study group. However, the proportion of those who were positive throughout all three QFTs dropped to 14.3\% (36/252) from $24.2 \%(162 / 670)$ with two positive consecutive QFTs in the whole group. Two (10\%) reversions (one transient reversion-second QFT negative and third QFT positive) were observed in those with a baseline INF- $\gamma$ concentration $\geq 3.0 \mathrm{IU} / \mathrm{mL}$, while $73.3 \%$ showed a reversion at the second $(n=10)$ or the third $(n=1)$ QFT when the baseline INF- $\gamma$ concentration was $\geq 0.35$ to $<0.7 \mathrm{IU} / \mathrm{mL}$. In addition, one (6.7\%) transient reversion occurred. In Figs. 1 and 2, the association between baseline INF- $\gamma$ concentration and reversion or conversion can also be seen. The median of the baseline INF- $\gamma$ concentration was $\geq 0.1 \mathrm{IU} / \mathrm{mL}$ in those with conversion in the second or in the third QFT (Fig. 1). Only one reversion occurred when the baseline INF- $\gamma$ concentration was above $3.0 \mathrm{IU} / \mathrm{mL}$ (see asterisk in Fig. 2).

The time between the first and second QFT was, on average, 11.5 months (standard deviation 4.0 months). The time between the first and third QFT was, on average, 19.8 months (standard deviation 5.5 months). No association was observed between the time span of the QFTs and 
Table 4 Number and rate of conversions and reversions depending on different definitions for 'true' conversions and 'true' reversions

Source population: Those who fulfilled the first condition (positive or negative first test) of the different definitions for conversion and reversion

$N$ absolute number of converted or reverted HCWs

$\%$ annual rate of reversions and conversions

95\% CI 95\% confidence interval
Definition of (a) conversion (b) reversion

\begin{tabular}{lrrc}
$\begin{array}{l}\text { Source } \\
\text { population }\end{array}$ & $N$ & $\%$ & $95 \% \mathrm{CI}$ \\
462 & 51 & 11.0 & $8.3-14.3$ \\
208 & 46 & 22.1 & $16.7-28.4$ \\
421 & 15 & 3.6 & $2.0-5.8$ \\
153 & 8 & 5.2 & $5.3-10.0$ \\
462 & 41 & 8.9 & $6.4-11.8$ \\
208 & 33 & 15.9 & $11.2-21.6$ \\
462 & 31 & 6.7 & $4.6-9.4$ \\
208 & 21 & 10.1 & $6.4-15.0$ \\
& & & \\
199 & 61 & 30.7 & $24.3-37.6$ \\
188 & 4 & 2.1 & $0.6-5.4$ \\
199 & 98 & 49.2 & $42.1-56.4$ \\
188 & 7 & 3.8 & $1.5-7.5$ \\
\hline
\end{tabular}

Table 5 Results of second and third QFT depending on INF- $\gamma$ concentration in first QFT

\begin{tabular}{|c|c|c|c|c|c|}
\hline \multirow{3}{*}{$\begin{array}{l}\text { 1st QFT } \\
\text { (IU/mL) }\end{array}$} & \multicolumn{4}{|c|}{ 2nd and 3rd QFT } & \multirow{3}{*}{$\begin{array}{l}\text { Total } \\
N(\%)\end{array}$} \\
\hline & -- & ++ & +- & -+ & \\
\hline & $N(\%)$ & $N(\%)$ & $N(\%)$ & $N(\%)$ & \\
\hline \multirow[t]{2}{*}{$<0.1$} & 139 & 4 & 5 & 7 & 155 \\
\hline & 89.7 & 2.6 & 3.2 & 4.5 & 78.7 \\
\hline \multirow[t]{2}{*}{$0.1 \leq 0.2$} & 12 & 4 & 2 & 3 & 21 \\
\hline & 57.1 & 19.0 & 9.5 & 14.3 & 10.7 \\
\hline \multirow[t]{2}{*}{$0.2 \leq 0.35$} & 7 & 6 & 5 & 3 & 21 \\
\hline & 33.3 & 28.6 & 23.8 & 14.3 & 10.7 \\
\hline \multirow[t]{2}{*}{ Neg. 1st QFT } & 158 & 14 & 12 & 13 & 197 \\
\hline & 80.2 & 7.1 & 6.1 & 6.6 & $100.0(78.2)$ \\
\hline \multirow[t]{2}{*}{$0.35 \leq 0.7$} & 10 & 3 & 1 & 1 & 15 \\
\hline & 66.6 & 20.0 & 6.7 & 6.7 & 27.3 \\
\hline \multirow[t]{2}{*}{$0.7-1.0$} & 1 & 4 & 1 & 0 & 6 \\
\hline & 16.7 & 66.7 & 16.7 & - & 10.9 \\
\hline \multirow[t]{2}{*}{$>1-3$} & 2 & 11 & 1 & 0 & 14 \\
\hline & 14.3 & 78.6 & 7.1 & - & 25.5 \\
\hline \multirow[t]{2}{*}{$>3$} & 1 & 18 & 0 & 1 & 20 \\
\hline & 5.0 & 90.0 & - & 5.0 & 36.4 \\
\hline \multirow[t]{2}{*}{ Pos. 1st QFT } & 14 & 36 & 3 & 2 & 55 \\
\hline & 25.5 & 65.5 & 5.5 & 3.6 & $100.0(21.8)$ \\
\hline \multirow[t]{2}{*}{ All } & 172 & 50 & 15 & 15 & 252 \\
\hline & 68.3 & 19.8 & 6.0 & 6.0 & 100.0 \\
\hline
\end{tabular}

the probability of conversion or reversion in the QFT (data not shown).

Nine HCWs were diagnosed with active TB, all but two were acid-fast bacillus (AFB)-positive, culturally confirmed cases. In one person, diagnosis was based solely on

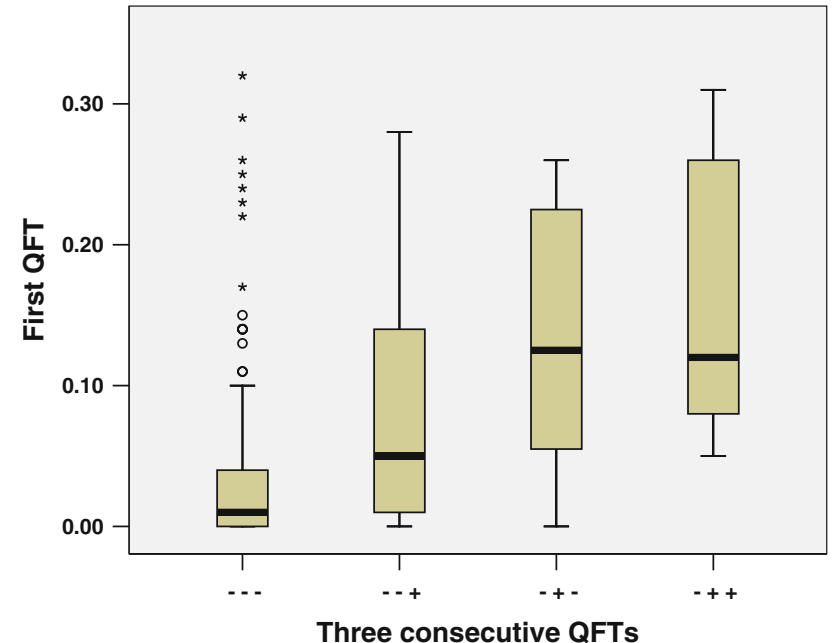

Fig. 1 Box plot for INF- $\gamma$ concentration of the first QFT depending on whether all three consecutive QFTs were negative $(---)$, the third QFT became positive $(--+)$, only the second QFT was positive $(-+-)$ or the two following QFT were positive $(-++)$ for the subgroup with a negative first QFT $(n=197)$

PCR (Table 6). All persons with active TB were positive in the first QFT. The TST was $\geq 15 \mathrm{~mm}$ in seven and $10-14 \mathrm{~mm}$ in two of them. Seven HCWs had pulmonary TB, one pleural TB, and one skin TB. Six active TB cases were diagnosed within 2 months of the first QFT. The other three cases were diagnosed three, seven, and 19 months after the first positive QFT. In one case, a second QFT was performed at the time of diagnosis 3 months after the first QFT and an increase from 0.51 to $1.96 \mathrm{IU} / \mathrm{mL}$ was observed. The median of the INF- $\gamma$ concentration in those with actual pulmonary $\mathrm{TB}$ was $2.26 \mathrm{IU} / \mathrm{mL}$, the minimum was $0.51 \mathrm{IU} / \mathrm{mL}$, and the maximum $6.32 \mathrm{UI} / \mathrm{mL}$. For the HCW with pleural TB the INF- $\gamma$ in the first 


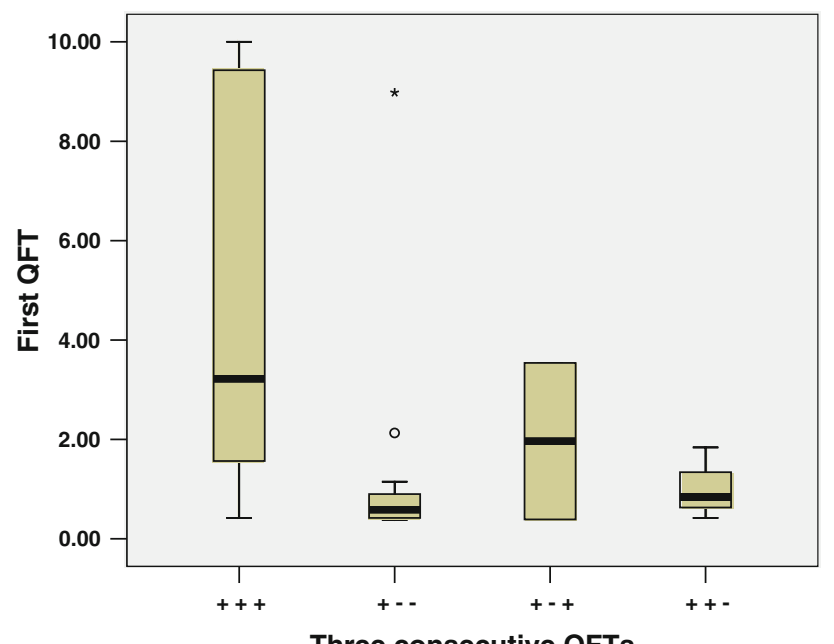

Three consecutive QFTs

Fig. 2 Box plot for INF- $\gamma$ concentration of the first QFT depending on whether all three consecutive QFTs were positive $(+++)$, the second and third QFT became negative $(+--)$, only the second QFT was negative $(+-+)$ or the third QFT became negative $(++-)$ for the subgroup with a positive first QFT $(n=55)$

QFT was $0.42 \mathrm{IU} / \mathrm{mL}$ and in the skin TB case it was $>10 \mathrm{IU} / \mathrm{mL}$. After diagnosis and treatment, a reversion occurred in the patient with pleural TB and a sharp decline occurred in the HCW with cutaneous TB $(>10$ $1.04 \mathrm{IU} / \mathrm{mL})$. For the other six cases, increases and decreases of INF- $\gamma$ concentration were observed three times, respectively. A positive QFT led to diagnosis in four HCWs with no symptoms. In the other $5 \mathrm{HCWs}$ with pulmonary, active TB, typical symptoms such as cough, fever, weakness, or weight loss were observed along with a positive QFT.

\section{Discussion}

Our study is the largest follow-up study for serial testing to date. Furthermore, it is also the only study on serial testing that actually observed active TB cases, thus allowing conclusions about test interpretation in serial testing to be based on these findings. As suggested in smaller studies before (Pai et al. 2006; Pai et al. 2009; Hill et al. 2007; Franken et al. 2007; Yoshiyama et al. 2009; van Zyl-Smit et al. 2009), our data shows that a simple positive/negative approach in the interpretation of the IGRA might be misleading because of a high number of spontaneous conversions and reversions originating from INF- $\gamma$ concentrations close to the cutoff for the QFT. Using an uncertainty zone around the cutoff would help to distinguish between clinically unimportant variation and true conversion and reversion. If one of the consecutive QFTs falls into this uncertainty zone, conversion or reversion is doubtful. On the basis of our data, the lower limit of the uncertainty zone could be $0.2 \mathrm{IU} / \mathrm{mL}$ and the upper limit $0.7 \mathrm{IU} / \mathrm{mL}$ because this provides the sharpest decrease in conversion and reversion rates. Even though a reversion rate with initial INF- $\gamma$ concentration between 0.7 and $\leq 1.0$ was high (17.4\%), the uncertainty zone should not be extended to this range because we observed an active pulmonary TB with an INF- $\gamma$ concentration of $0.92 \mathrm{IU} / \mathrm{mL}$.

The conversion rate $(11 \%)$ we observed was similar to those reported for Indian HCWs (11.6\%) (Pai et al. 2006). In the Japanese HCW study, the conversion rate was lower (1.7\%) (Yoshiyama et al. 2009). In a recent German HCW study, the conversion rate was $1.9 \%$ (Ringshausen et al. 2010). When applying the gray zone and defining a conversion as a transgression from $<0.2$ to $>0.7 \mathrm{IU} / \mathrm{mL}$, the

Table 6 Characteristics of the 9 HCWs diagnosed with active TB

\begin{tabular}{|c|c|c|c|c|c|c|c|}
\hline $\mathrm{TB}$ & Gender & Age & TST mm & 1st QFT IU/mL & $\begin{array}{l}\text { Months between } \\
\text { 1st QFT and diagnosis }\end{array}$ & $\begin{array}{l}\text { 2nd QFT } \\
\mathrm{IU} / \mathrm{mL}\end{array}$ & $\begin{array}{l}\text { Symptoms } \\
\text { at first QFT }\end{array}$ \\
\hline Pneumal & Female & 26 & 17 & 0.51 & 3 & $1.96^{*}$ & None \\
\hline Pneumal & Female & 39 & 18 & 3.97 & $<1$ & 6.29 & None \\
\hline Pneumal & Female & 25 & 16 & 6.32 & 19 & 1.30 & Cough \\
\hline Pneumal & Female & 29 & 17 & 2.11 & $<1$ & 3.28 & Cough \\
\hline Pneumal & Female & 25 & 13 & 1.30 & $<1$ & 1.22 & Cough, fever \\
\hline Pneumal & Female & 31 & 22 & 0.92 & 7 & 0.56 & $\begin{array}{c}\text { Cough, weakness, } \\
\text { weight loss }\end{array}$ \\
\hline Pneumal & Female & 25 & 14 & 2.41 & $<2$ & 3.57 & None \\
\hline Pleural $^{\mathrm{a}}$ & Male & 26 & 20 & 0.42 & $<1$ & 0.10 & None \\
\hline Cutaneous $^{\mathrm{b}}$ & Female & 50 & 21 & $>10$ & $<1$ & 1.04 & Skin lesion \\
\hline
\end{tabular}

* In all but the first case, the second QFTs were performed after diagnosis

a Positive PCR, if not indicated otherwise all cases were AFB-positive and culturally confirmed

${ }^{\mathrm{b}}$ Culturally confirmed 
conversion rate decreased from 11 to $3.6 \%$. We believe the lower conversion rate to be more realistic because Portugal is a country with medium TB incidence comparable to Japan, while India is a high-incidence country. Therefore, most conversions we observed are unlikely to be explained by an increased replication rate of MTB (reactivation) or new infection with MTB.

A conversion in TST (increase $\geq 10 \mathrm{~mm}$ ) occurred about three times as often as a conversion in QFT (30.7\% versus $11 \%)$. Therefore, TST most likely overestimated the conversion rate. Independent of the criteria, conversion of TST was not predictive of a positive QFT. Three out of four HCWs who fulfilled the criteria for TST conversion were negative in the QFT. This casts some doubt on the validity of the change criteria in serial testing with TST.

The reversion rate $(22.1 \%)$ we observed was similar to those reported for Indian HCWs (24\%) (Pai et al. 2006). In the Japanese HCW study, the reversion rate was higher (52.6\%) (Yoshiyama et al. 2009). In this study, $80 \%$ (eight out of ten) of the reversions had at least one INF- $\gamma$ concentration falling into the above-defined uncertainty zone. In our data, spontaneous reversions were rare $(4.1 \%)$ when baseline INF- $\gamma$ concentration was $>7.0 \mathrm{IU} / \mathrm{mL}$. The reversion rate for a baseline INF- $\gamma$ concentration between 1.0 and $3.0 \mathrm{IU} / \mathrm{mL}$ observed by us was about the same as that observed in the Indian household contact study (18.9 versus 17\%) (Pai et al. 2009). Even though this reversion rate is high and is therefore unlikely to be explained by true reversion (transition from $\mathrm{T}$-cell stimulating replication to dormant state of MTB), a QFT $\geq 1.0$ should be considered as indicative of LTBI because four out of our eight active TB cases had baseline INF- $\gamma$ concentrations between 1.0 and $3.0 \mathrm{IU} / \mathrm{mL}$. One reason for the reversion rate being higher than the conversion rate $(22.1 \%$ versus $11 \%)$ might be the 'tendency toward the mean'. In repeated testing, random measurement errors tend to draw the results toward the mean, which in our study was below $0.35 \mathrm{I} \mathrm{U} / \mathrm{mL}$. Our data suggest that this random measurement error is particularly import around the cutoff.

A reversion in TST occurred five to ten times less often than a reversion in QFT. Reversion in TST was not associated with reversion in QFT. Most often, those with a reversion in TST were negative in both consecutive QFTs. However, our data on reversion in TST is too sparse to draw any meaningful conclusions.

Variability of INF- $\gamma$ concentration is influenced by several factors: intra-individual short-term variations of test results, variation in precision of measurement techniques, insufficient standardization of the handling of the probes. Variations caused by these factors can hardly be distinguished from variations caused by immunologic responses to increasing or decreasing replication of MTB in the persons infected. So far, only one study has measured short- term variations in IGRA results. However, this study was performed in a high-incidence country (van Zyl-Smit et al. 2009). Therefore, it was not possible to distinguish between random variation of INF- $\gamma$ and immunologic response to MTB exposure. As a limitation of our data, we did not collect data on variables that might influence the QFT results. In future, studies are needed which analyze intra-individual variation of IGRA results and risk factors for this variation (e.g. alcohol consumption, time of test). Furthermore, variation of test results due to handling variations, different test kits or other technical aspects of the laboratory procedures should be analyzed.

Studies on TB prediction by QFTs show promising results in low to intermediate TB incidence countries (Diel et al. 2008; Aichelburg et al. 2009; Yoshiyama et al. 2010). In the Japanese prediction study, risk of progression to active TB increased with the concentration of QFT (Yoshiyama et al. 2010). So far, there is no study available that describes the association between the changes in IGRA and disease prediction. Only one of our nine TB cases was diagnosed after a second QFT was performed. In this patient, both QFTs were positive, with an increase from 0.51 to $1.96 \mathrm{UI} / \mathrm{mL}$. This gives limited support to the hypothesis that QFT variations might be predictive of TB progression risk.

When using an uncertainty zone of $0.2-0.7 \mathrm{IU} / \mathrm{mL}$, it should be kept in mind that a QFT result around the cutoff $(0.35 \mathrm{IU} / \mathrm{mL})$ does not exclude active TB. We observed a pleural TB patient with an INF- $\gamma$ concentration of $0.42 \mathrm{IU} / \mathrm{mL}$. It is known that INF- $\gamma$ response in peripheral blood might be low in pleural TB patients (Hooper et al. 2009). Therefore, this observation was not surprising. Furthermore, we observed active pulmonary $\mathrm{TB}$ in an HCW with a positive first QFT falling into the uncertainty zone and a second QFT clearly above the uncertainty zone. It tells us that when using an uncertainty zone in serial testing, this should be done with the greatest of care. Uncertainty zone means that spontaneous, clinically irrelevant transgressions over the cutoff are probably predominant, but it does not exclude LTBI or even active TB. Sensitivity studies for QFT using active TB as a surrogate for LTBI suggest that disease activity might be inversely related to INF- $\gamma$ concentration (Menzies et al. 2007; Diel et al. 2010). Therefore, as with the TST, recent exposure and clinical symptoms must be taken into account when interpreting QFT results.

Progression rate for active TB is highest in the first 2 years after exposure. Therefore, preventive treatment is most effective if recent infection is likely. In those with a positive QFT result falling into the gray zone and recent accidental and unprotected contact with infectious patients or materials, QFT should be repeated within 4 weeks after 
the first test. If QFT remains positive, preventive treatment should be initiated. If screening was performed because of regular contact with TB patients or infectious materials and therefore a distinction between old or recent LTBI is not possible, the next routine screening and therefore the next IGRA should be performed in 1 year. This recommendation is based on weak evidence. It should be borne in mind that low concentrations in QFT do not exclude progression to active TB, as was observed in the above-mentioned Japanese prediction study (Yoshiyama et al. 2010). However, disease progression was more likely with higher INF- $\gamma$ concentrations in QFT. In future, studies are needed that analyze progression risk depending on IGRA results, changes in IGRA results, and exposure history.

Despite our increasing knowledge, several key questions about latent infection and reactivation of $M$. tuberculosis remain unanswered. Particularly, it should be noted that both the TST and the IGRA are designed to identify an adaptive immune response against $M$. tuberculosis, but not necessarily a latent infection. A positive result of currently available diagnostic tests is primarily a measure of an immunologic response to stimulation by mycobacterial antigens that should not, therefore, be equated with the presence of live M. tuberculosis in the human host. The proportion of individuals who truly remain infected with $M$. tuberculosis after TST or IGRA conversion is unknown. It is also uncertain how long adaptive immune responses toward mycobacterial antigens persist in the absence of live mycobacteria. For these reasons, according to the recently published TBNET consensus statement regarding latent TB and based on the informative value currently derived by IGRA and TST, the term "latent infection" would at best implicate "lasting tuberculosis immune responses" and would not necessarily identify a true latent infection with viable microorganisms and potential risk of developing active disease (Mack et al. 2009).

In conclusion, our data suggests the use of an uncertainty zone between 0.2 and $0.7 \mathrm{IU} / \mathrm{mL}$ in serial testing with QFT. As long as our knowledge regarding disease progression in QFT-positive persons is limited, in countries with limited experience in chemoprevention, persons pertaining to the uncertainty zone should be retested before being offered preventive chemotherapy.

Acknowledgments We want to thank the HCWs of the Hospital S. João for their participation in the study. The authors declare that they do not have any competing interests. No funds were received for the study.

Open Access This article is distributed under the terms of the Creative Commons Attribution Noncommercial License which permits any noncommercial use, distribution, and reproduction in any medium, provided the original author(s) and source are credited.

\section{References}

Aichelburg MC, Rieger A, Breitenecker F, Pfistershammer K, Tittes J, Eltz S, Aichelburg AC, Stingl G, Makristathis A, Kohrgruber N (2009) Detection and prediction of active tuberculosis disease by a whole-blood interferon-gamma release assay in HIV-1-infected individuals. Clin Infect Dis 48:954-962

ATS American Thoracic Society (2000) Targeted tuberculin testing and treatment of latent tuberculosis infection. Am J Respir Crit Care Med 161(Suppl):S221-S247

CDC Center for Disease Control and Prevention (2005) Guidelines for preventing the transmission of Mycobacterium tuberculosis in healthcare settings. 2005 MMWR 54 (No. RR-17):1-141

Cummings KJ, Smith TS, Shogren ES, Khakoo R, Nanda S, Bunner L, Smithmyer A, Soccorsi D, Ksahon ML, Mazurek GH, Friedman LN, Weissman DN (2009) Prospective comparison of tuberculin skin test and QuantiFERON-TB gold in-tube assay for the detection of latent tuberculosis infection among healthcare workers in a low-incidence setting. Infect Control Hosp Epidemiol 30(11):1123-1126

Diel R, Ernst M, Doscher G, Visuri-Karbe L, Greinert U, Niemann S, Nienhaus A, Lange C (2006) Avoiding the effect of BCG vaccination in detecting Mycobacterium tuberculosis infection with a blood test. Eur Respir J 28(1):16-23

Diel R, Loddenkemper R, Meywald-Walter K, Niemann S, Nienhaus A (2008) Predictive value of a whole blood IFN-\{gamma $\}$ assay for the development of active TB disease. Am J Respir Crit Care Med 177:1164-1170

Diel R, Loddenkemper R, Nienhaus A (2010) Evidence based comparison of commercial interferon gamma release assays for detecting active tuberculosis - a systematic review. Chest 137(4):952-968

Ewer K, Millington KA, Deeks JJ, Alvarez L, Bryant G, Lalavani A (2006) Dynamic antigen-specific T-cell responses after pointsource exposure to Mycobacterium tuberculosis. Am J Respir Crit Care Med 174:831-839

Franken WPJ, Koster BFPJ, Bosnik AWJ, Thijsen SFT, Bouwman JJM, van Dissel JT, Arend SM (2007) Follow-up study of tuberculosis-exposed supermarket customers with negative tuberculin skin test results in association with positive gamma interferon release assay results. Clin Vaccine Immunol 14(9):1239-1241

Hill PC, Jeffries DJ, Brookes RH, Fox A, Jackson-Sillah D, Lugos MD, Donkor SA, de Jong BC, Corrah T, Adegbola RA, McAdam KP (2007) Using ELISPOT to expose false positive skin test conversion in tuberculosis contacts. PLoS ONE 2(1):e183

Hooper CE, Lee YC, Maskell NA (2009) Interferon-gamma release assays for the diagnosis of TB pleural effusions: hype or real hope? Curr Opin Pulm Med 15(4):358

Mack U, Migliori GB, Sester M, Rieder HL, Ehlers S, Goletti D, Bossink A, Magdorf K, Hölscher C, Kampmann B, Arend SM, Detjen A, Bothamley G, Zellweger JP, Milburn H, Diel R, Ravn P, Cobelens F, Cardona PJ, Kann B, Solovic I, Duarte R, Cirillo DM, Lange C for the TBNET. LTBI (2009) LTBI: latent tuberculosis infection or lasting immune responses to M. tuberculosis?A TBNET consensus statement. Eur Respir J 33:956-73

Menzies D (1999) Interpretation of repeated tuberculin tests. Boosting, conversion and reversion. Am J Respir Crit Care Med 159:15-21

Menzies D, Pai M, Comstock G (2007) Meta-analysis: new tests for the diagnosis of latent tuberculosis infection: areas of uncertainty and recommendations for research. Ann Intern Med 146:340-352

National Vaccination Plan (2009) Programa Nacional de Vacinação (accessed April 1st, 2010) Direcção-Geral da Saúde-Ministério da Saúde http://www.dgs.pt/upload/membro.id/ficheiros/i007442.pdf

Nienhaus A, Schablon A, Diel R (2008) Interferon- $\gamma$ release assay for the diagnosis of latent TB infection-analysis of discordant results, when compared to the tuberculin skin test. PLoS ONE 3(7):e2665 
Pai M, Joshi R, Dogra S, Mendriatta DK, Narang P, Kalantri S, Reingold AL, Colford JM, Riley LW, Menzies D (2006) Serial testing of health care workers for tuberculosis using inferferon- $\gamma$ assay. Am J Respir Crit Care Med 174:349-355

Pai M, Dheda K, Cunningham J, Scano F, O'Brien R (2007) T-cell assays for the diagnosis of latent tuberculosis infection: moving the research agenda forward. Lancet Infect Dis 7:428-438

Pai M, Joshi R, Dogra S, Zwerling AA, Gajalakshmi D, Goswami K, Reddy MVR, Kalantri S, Hill PC, Menzies D, Hopewell PC (2009) T-cell assay conversions and reversions among household contacts of tuberculosis patients in rural India. Int J Tuberc Lung Dis 13(1):84-92

Ringshausen F, Nienhaus A, Schablon A, Schlosser S, Schultze-Werninghaus G, Rohde G (2010) Predictors of persistently positive Mycobacterium-tuberculosis-specific interferon-gamma responses in the serial testing of health care workers. BMC Infectious Diseases 10:220

Seidler A, Nienhaus A, Diel R (2005) Review of epidemiological studies on the occupational risk of tuberculosis in low-incidence areas. Respiration 72(4):431-446
Torres Costa J, Sá R, Cardoso MJ, Silva R, Ferreira J, Ribeiro C, Miranda M, Plácido JL, Nienhaus (2009) Tuberculosis screening in Portuguese healthcare workers using the tuberculin skin test and the Interferon- $\gamma$ release assay. Eur Resp J 34:1423-1428

van Zyl-Smit R, Pai M, Peprah K, Meldau R, Meldau R, Kieck J, Juritz J, Badri M, Zumla A, Sechi LA, Bateman ED, Dheda K (2009) Within-subject variability and boosting of T-cell Interferon- $\gamma$ responses after tuberculin skin testing. Am J Respir Crit Care Med 180:49-58

Yoshiyama T, Harada N, Higuchi K, Nakajima Y, Ogata H (2009) Estimation of incidence of tuberculosis infection in health-care workers using repeated interferon-gamma assays. Epidemiol Infect $1-8$

Yoshiyama T, Harada N, Higuchi K, Sekiya Y, Uchimura K (2010) Use of the QuantiFERON-TB gold test for screening tuberculosis contacts and predicting active disease. Int $\mathbf{J}$ Tuberc Lung Dis 14(7):819-827 